\title{
Intradural ventral and ventrolateral tumors of the spinal cord: surgical treatment and results
}

\author{
Eugene I. Slin’ko, M.D., Ph.D., AND Iyad Ischak Al-QAShQish, M.D. \\ Institute of Neurosurgery, Kiev, Ukraine
}

\begin{abstract}
Object. To improve results of surgical treatment of ventral and ventrolateral tumors of the spinal cord, the authors analyzed surgical approaches, defined the indications for various approaches, and assessed the clinical results.

Methods. Between 1993 and 2004 the authors treated 360 patients: 43 of them had dorsal, 177 dorsolateral, 33 ventral, and 107 had ventrolateral intradural extramedullary tumors. Among 140 patients with intradural extramedullary ventral and ventrolateral tumors, neuromas were seen in 56 and meningiomas in 84. Of the 140 patients studied, tumors were removed totally in $102(74 \%)$, subtotally in 30 (21\%), and partially in eight $(5 \%)$. After ventrolateral and dorsolateral approaches were introduced in 1996, tumors in ventral or ventrolateral locations have been removed totally or subtotally. In the group of patients with meningiomas, 41 of the lesions were the meningothelial type, 22 were transitional, 12 fibroblastic, four psammomatous, three were angiomatous, one was atypical, and one was malignant. Tumors in the neuroma group were schwannomas in 45 patients and neurofibromas in 11. Postoperatively, recovery was observed in 70 patients (50\%), improvement in $53(38 \%)$, no change in $10(7 \%)$, and deterioration in seven (5\%). At follow-up evaluation recovery was noted in 76 patients, improvement in 58, no change in four, and in two patients the neurological symptoms were worse than before the operation.

Conclusions. Surgical routes to extramedullary tumors should be chosen based on the location of the tumor, its spread, and the region in which it is localized.
\end{abstract}

\section{KEY WORDS • spinal cord • tumor • neuroma • meningioma • surgical approach • microsurgery}

On the whole, intradural extramedullary spinal cord tumors are no longer a problem for neurosurgical treatment. Nevertheless, the tumors localized ventrally to the spinal cord are difficult to remove surgically and are often accompanied by insufficient tumor visualization, which can lead to intraoperative spinal cord trauma during removal of these lesions. The total removal of these tumors is not always possible, ${ }^{1,3-5}$ and aggravation of neurological signs after surgery is not rare. Various posterior approaches are used traditionally to remove these tumors. Anterolateral approaches for such tumors represent an essential technical problem; they are accompanied by intensive bleeding from epidural veins that obscures the visibility of these tumors. Difficulties also arise in the planning of adequate bone resections for complete visualization of these tumors from an anterior approach. To study the surgical tactics, peculiarities of approaches, and techniques of removing of these tumors as well as the results of their surgical treatment we have conducted an analysis of such operations for the period from 1993 to 2004.

\section{CLINICAL MATERIAL AND METHODS}

In compliance with the generally accepted classification

Abbreviations used in this paper: $\mathrm{CSF}=$ cerebrospinal fluid; $\mathrm{MR}=$ magnetic resonance. we divided all intradural extramedullary tumors in the spinal cord into the following categories: 1) dorsal; 2) dorsolateral; 3) lateral; 4) ventrolateral; and 5) ventral. ${ }^{2,5} \mathrm{Be}-$ tween 1993 and 2004 we treated 360 patients in whom 43 had dorsal, 177 dorsolateral, 33 ventral, and 107 ventrolateral intradural extramedullary tumor localization (Table 1). We chose the ventral and ventrolateral intradural extramedullary tumors for in-depth study. In this group of 140 patients, 56 had neuromas and 84 had meningiomas. The patients' ages ranged from 25 to 80 years. The mean age of the patients with meningiomas was 60 years and that of the patients with neuromas was 50 years.

The regions of localization of the extramedullary spinal tumors were as follows: 1) tumors in the upper cervical region $(\mathrm{C} 1-4) ; 2)$ tumors in the lower cervical region (C5$\mathrm{T} 1)$; 3) tumors in the thoracic region (T2-10); and 4) tumors in the thoracolumbar region (T11-L1). Thirty-four tumors were found in the upper cervical spine (13 meningiomas and 21 neuromas); 23 were found in the region of the lower cervical spine (15 meningiomas and eight neuromas); 54 were found in the region of the thoracic spine (40 meningiomas and 14 neuromas); and 29 were found in the thoracolumbar region (16 meningiomas and 13 neuromas). Of all cases studied, meningiomas made up $60 \%$ and neuromas $40 \%$ (Table 2). In 107 patients (76\%), the tumor's location was ventrolateral and in 33 patients (24\%) it was ventral (Table 3).

At the time of operation, motor and sensory distur- 
TABLE 1

Location of intradural extramedullary tumors in 360 patients with spinal cord lesions

\begin{tabular}{lrcccr}
\hline \hline \multicolumn{1}{c}{ Location } & Dorsal & Dorsolateral & Ventral & Ventrolateral & Total \\
\hline cervical & 4 & 24 & 14 & 43 & 85 \\
thoracic & 36 & 138 & 9 & 45 & 228 \\
thoracolumbar & 3 & 15 & 10 & 19 & 47 \\
total & 43 & 177 & 33 & 107 & 360 \\
\hline
\end{tabular}

bances were noted in 125 patients $(89 \%)$, bowel or bladder dysfunction was found in $86(61 \%)$, and pain was present in $102(73 \%)$. The diagnosis was established with the use of myelography, MR imaging, computerized tomography scanning, spinal selective angiography, and MR imaging with Magnevist intensification.

\section{RESULTS}

To make the diagnosis more accurate and to choose the optimum surgical approach in patients in whom extramedullary spinal cord tumor was suspected, the following investigations were performed: 1) 1.5-tesla MR imaging in the sagittal, frontal, and axial planes, $\mathrm{T}_{1}$ - and $\mathrm{T}_{2}$-weighted images; 2) MR angiography; 3) computerized tomography scans with or without contrast agents performed to obtain differential diagnostics for extramedullary intradural tumors and tumors with epidural spreading affecting vertebrae; 4) vertebral and spinal selective angiography performed in cases of large tumors when MR imaging demonstrated the vascular nature of the tumor and when there were plentiful flow-void areas.

Three surgical approaches were used: dorsal, dorsolateral, and ventrolateral (Fig. 1). As shown in Tables 4 through 6, midline dorsal access was used in 43 patients (24 with meningiomas and 19 with neuromas); dorsolateral access in 85 patients (55 with meningiomas and 30 with neuromas); and ventrolateral access 12 patients (five with meningiomas and seven neuromas). The dorsal approach was performed according to the tumor location: in four patients with tumors in the cervical region; in 28 with lesions in the thoracic region, and in 11 with tumors in the
TABLE 3

Intradural extramedullary ventral and ventrolateral location of the 140 tumors studied according to region

\begin{tabular}{lccc}
\hline \hline \multicolumn{1}{c}{ Location } & Ventral & Ventrolateral & Total \\
\hline cervical & 14 & 43 & 57 \\
thoracic & 9 & 45 & 54 \\
thoracolumbar & 10 & 19 & 29 \\
total (\%) & $33(24)$ & $107(76)$ & 140 \\
\hline
\end{tabular}

thoracolumbar region. The dorsolateral approach was performed in 44 patients with the lesions in the cervical spine, in 24 with tumors in the thoracic spine, and in 16 with tumors in the lumbar spine. The ventrolateral approach was performed in nine patients with lesions in the cervical region, in one with a tumor in the thoracic region, and in two with lesions in the lumbar region. We ranked far-lateral access on the upper cervical spine as a version of the dorsolateral approach (Table 7). The dorsal approach included laminectomy and medial facetectomy on the side of the tumor. It was generally used for small ventrolateral tumors.

During the dorsolateral approach the intervertebral joints were removed completely, pedicles were sometimes removed, and at thoracic level transverse processes and rib heads were removed. This access was commonly used for ventral meningiomas or ventrolateral neuromas with dumbbell-shaped growth that only filled an intervertebral foramen. When a ventrolateral neuroma in the cervical region only filled an intervertebral foramen after complete facetectomy it was possible to separate the tumor safely from the vertebral artery and the vein accompanying it on direct vision.

We considered especially cases in which ventrolateral dumbbell-shaped neuromas grew ventrally through the intervertebral foramen and in which the tumor parts were located ventrally to the intervertebral foramen. In the thoracic region, if a small part of tumor was located ventrally to the intervertebral foramen, we planned a dorsolateral approach via an extrapleural or transpleural route. In the upper cervical region in such cases, the far-lateral approach was used. A similar situation in the cervical (below

TABLE 2

The intradural extramedullary ventral and ventrolateral spinal cord tumors treated in a 10-year period

\begin{tabular}{|c|c|c|c|c|c|c|c|c|c|c|c|c|c|c|c|c|c|c|c|c|c|c|c|}
\hline \multirow[b]{3}{*}{ Region } & \multicolumn{20}{|c|}{ Year } & \multirow{2}{*}{\multicolumn{2}{|c|}{ Subtotal }} & \multirow[b]{3}{*}{ Tota } \\
\hline & \multicolumn{2}{|c|}{1993} & \multicolumn{2}{|c|}{1994} & \multicolumn{2}{|c|}{1995} & \multicolumn{2}{|c|}{1996} & \multicolumn{2}{|c|}{1997} & \multicolumn{2}{|c|}{1998} & \multicolumn{2}{|c|}{1999} & \multicolumn{2}{|c|}{2000} & \multicolumn{2}{|c|}{2001} & \multicolumn{2}{|c|}{2002} & & & \\
\hline & $\mathrm{Neu}$ & $\mathrm{Me}$ & $\mathrm{Neu}$ & $\mathrm{Me}$ & Neu & $\mathrm{Me}$ & $\mathrm{Neu}$ & $\mathrm{Me}$ & Neu & $\mathrm{Me}$ & Neu $\mathrm{I}$ & $\mathrm{Me}$ & $\mathrm{Neu}$ & $\mathrm{u} \mathrm{Me}$ & Neu & $\mathrm{Me}$ & $\mathrm{Neu}$ & $\mathrm{Me}$ & $\mathrm{Neu}$ & $\mathrm{Me}$ & Neu & $\mathrm{Me}$ & \\
\hline $\begin{array}{l}\text { C1-4 (upper } \\
\text { cervical) }\end{array}$ & 4 & 1 & 1 & 2 & 2 & 3 & 2 & 3 & & & 2 & & 3 & & 3 & 2 & & & 4 & 2 & 21 & 13 & 57 \\
\hline $\begin{array}{l}\text { C5-T1 (lower } \\
\text { cervical) }\end{array}$ & 2 & 1 & & 1 & 1 & 3 & & 2 & & & 1 & 2 & 1 & 1 & 1 & & 2 & 4 & & 1 & 8 & 15 & \\
\hline T2-10 (thoracic) & 4 & 8 & 1 & 3 & & 5 & 3 & 3 & 1 & 3 & 1 & 2 & 3 & 5 & & 4 & 1 & 2 & & 5 & 14 & 40 & 83 \\
\hline $\begin{array}{l}\text { T11-L1 (tho- } \\
\text { racolumbar) }\end{array}$ & 1 & 2 & & & 2 & 2 & 1 & & 2 & 3 & 2 & 2 & & 1 & 2 & 2 & 3 & 1 & & 3 & 13 & 16 & \\
\hline subtotal & 11 & & 2 & 6 & 5 & 13 & 6 & 8 & 3 & 6 & 6 & 6 & & 7 & 6 & 8 & 6 & 7 & & 11 & & 84 & 140 \\
\hline total & 23 & & $\varepsilon$ & 8 & 18 & & 1 & 4 & s & 9 & 12 & & 14 & 14 & 1 & 14 & 13 & & 15 & 5 & 14 & & \\
\hline
\end{tabular}

$* \mathrm{Me}=$ meningioma; $\mathrm{Neu}=$ neuroma 

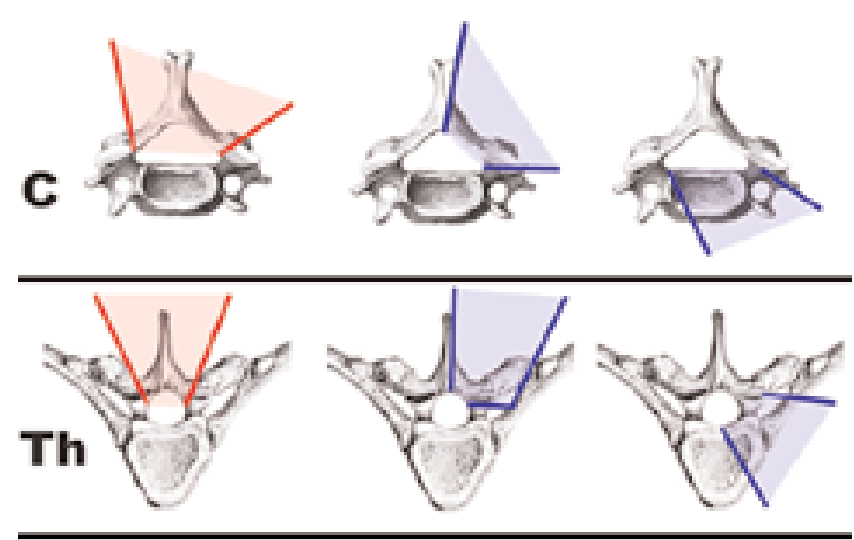

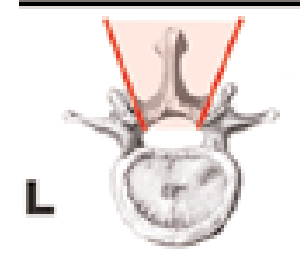

Dorsal

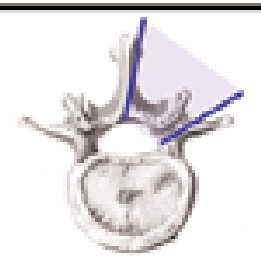

Dersolateral

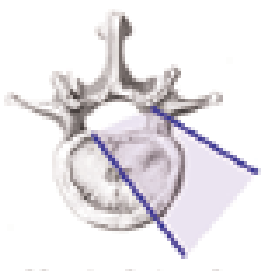

Ventrolateral
Fig. 1. Schema of dorsal, dorsolateral, and ventrolateral approaches, that we used for resection of spinal cord tumors at different levels. $\mathrm{C}=$ cervical; $\mathrm{L}=$ lumbar; $\mathrm{Th}=$ thoracic.

C-3) or lumbar region was an indication for the anterolateral approach. In these regions if the dorsolateral approach was undertaken, the ventral part of tumor was obscured from direct vision, and its removal was performed somewhat blind. In the cervical region, because of the vicinity of the vertebral artery and vertebral vein, in the lumbar segmental veins coursing to vena cava such blind removal may cause uncontrollable bleeding. If the ventrolateral approach was undertaken in cases of neuromas, during the surgical procedure the extravertebral part of the neuroma was removed first, and then the part of the tumor located in the intervertebral foramen. The next step was widening the intervertebral foramen with Kerrison forceps and removing the component of the tumor located in the foramen. The dural ring of the nerve root was opened and the ventral tumor mass was extracted after debulking.

Opening the dura through the intervertebral foramen was difficult, and it was even more difficult to close it. The leakage of CSF in a thoracic or retroperitoneal cavity can result in huge cysts and severe CSF hypotension. In the neck it was not a problem because there are no big

TABLE 4

Surgical approaches used to treat intradural extramedullary ventral spinal cord tumors

\begin{tabular}{lcccr}
\hline \hline & \multicolumn{4}{c}{ Ventral Tumor } \\
\cline { 2 - 5 } Approach & Cervical & Thoracic & Thoracolumbar & Total \\
\hline dorsal & 0 & 2 & 4 & 6 \\
dorsolateral & 7 & 6 & 5 & 18 \\
ventrolateral & 7 & 1 & 1 & 9 \\
total & 14 & 9 & 10 & 33 \\
\hline
\end{tabular}

TABLE 5

Surgical approaches used to treat intradural extramedullary ventrolateral spinal cord tumors

\begin{tabular}{lcccr}
\hline \hline & \multicolumn{4}{c}{ Ventrolateral Tumor } \\
\cline { 2 - 5 } Approach & Cervical & Thoracic & Thoracolumbar & Total \\
\hline dorsal & 4 & 26 & 7 & 37 \\
dorsolateral & 37 & 19 & 11 & 67 \\
ventrolateral & 2 & 0 & 1 & 3 \\
total & 43 & 45 & 19 & 107 \\
\hline
\end{tabular}

spaces, and the CSF leak closed spontaneously after lumbar drainage was performed. In any case, if the ventrolateral approach was necessary we used it: we expanded the intervertebral foramen as much as possible, carefully opened the dura, removed the tumor piecemeal aided by high magnification with an operating microscope, and closed the dura especially carefully. Then we established lumbar drainage. In cases involving large ventral meningiomas, ventrolateral access and resection of the vertebral body with its subsequent substitution was used. The distribution of approaches we used in cases of ventral and ventrolateral tumors is given in Tables 4 through 7.

When any of the aforementioned approaches was used, removal of the tumor was performed as follows: on approaching the dura mater, the epidural tissue was ablated and the epidural veins that were found were coagulated and sectioned. Further intervention was performed with the aid of an operating microscope. The dura was opened as follows: midline in the posterior approach; on the side of the tumor in the dorsolateral approach, a bit more dorsally from the dural root sleeves; and ventrolaterally in the ventrolateral approach. The arachnoid was dissected and retraction of the intradural contents was performed with a narrow spatula to discover the tumor. The vessels feeding the tumor were identified and coagulated. The tumor was completely separated from the arachnoid, and the place of initial tumor growth was found on the dura mater in cases of meningioma or in the nerve root in cases of neuroma. The central portion of the meningioma was then debulked, or if the shape of the tumor did not allow this it was partially resected by cutting it into pieces. After that the tumor was pushed away from the spinal cord toward its dural attachment and then removed from its dural attachment.

In large tumors, after the central part was debulked using ultrasound or cutting, the tumor capsule shrank and
TABLE 6

Surgical approaches used depending on histological type of tumor

\begin{tabular}{lccr}
\hline \hline & \multicolumn{3}{c}{ Tumor Type } \\
\cline { 2 - 4 } Approach & Meningioma & Neuroma & Total \\
\hline dorsal & 24 & 19 & 43 \\
dorsolateral & 55 & 30 & 85 \\
ventrolateral & 5 & 7 & 12 \\
total & 84 & 56 & 140 \\
\hline
\end{tabular}


TABLE 7

Surgical approaches used in different regions

\begin{tabular}{lrrrr}
\hline \hline & \multicolumn{4}{c}{ Region } \\
\cline { 2 - 5 } Approach & Cervical & Thoracic & Thoracolumbar & Total \\
\hline dorsal & 4 & 28 & 11 & 43 \\
dorsolateral & 44 & 25 & 16 & 85 \\
ventrolateral & 9 & 1 & 2 & 12 \\
total & 57 & 54 & 29 & 140 \\
\hline
\end{tabular}

was easily separated from the surrounding structures. In very dense small or large tumors, debulking was impossible and separation of the tumor from the spinal cord was difficult; it required traction of spinal cord. If possible, neuromas were separated from the affected nerve roots or the affected roots were coagulated and cut. In most cases meningiomas were easily separated from the dura mater, but if the tumor was firmly attached one of two approaches was used. 1) The remnants of the tu-mor were coagulated if they had not caused the spinal cord compression. 2) If they had caused compression, the remnants of the tumor were removed together with the dura mater.

Replacement of the dura was performed as follows. Restoration of dural integrity was accomplished by suturing the dura in cases in which there were no dural defects and the wound depth allowed suturing. In cases with dural defects we used fascia lata or artificial spinal membrane (Preclude; W. L. Gore \& Associates, Elkton, MD) stitching them into the defect. In cases in which suturing was impossible we glued the dural patch onto the hole.
The seam or dural patch was reinforced by gluing pieces of muscle over it. We encountered certain difficulties with completely ossified meningiomas. To avoid spinal cord trauma such tumors were removed in small pieces (Figs. 2-11).

The different surgical approaches, which were chosen based on the location of the tumor, allowed us to achieve more complete visualization of tumors, in other words to remove them under direct vision. Better visualization increased the number of completely resected tumors (Table $8)$. Tumors were totally removed in 102 cases $(74 \%)$, subtotally in $30(21 \%)$, and partially in eight $(5 \%)$ (Table 8). After the introduction of ventrolateral and dorsolateral approaches in 1996, ventral and ventrolateral tumors were no longer removed partially; all of them are removed totally or subtotally.

The following types of meningiomas were identified in the study group: 41 meningothelial, 22 transitional, 12 fibroblastic, four psammomatous, three angiomatous, one atypical, and one malignant. Partial ossification of the matrix or tumor capsule was found in 15 patients and complete ossification of the whole tumor node was found in four. Neuromas consisted of schwannomas in 45 patients and neurofibromas in 11.

Early results (assessed postoperatively but before the patient left the hospital) and follow-up results (2 months-9.2 years; mean 39 months postoperatively) included the following outcomes: recovery (complete disappearance of neurological signs), improvement, no change, and deterioration. In general, recovery was observed postoperation in 70 patients (50\%), improvement in $53(38 \%)$, no change in $10(7 \%)$, and deterioration in seven (5\%).
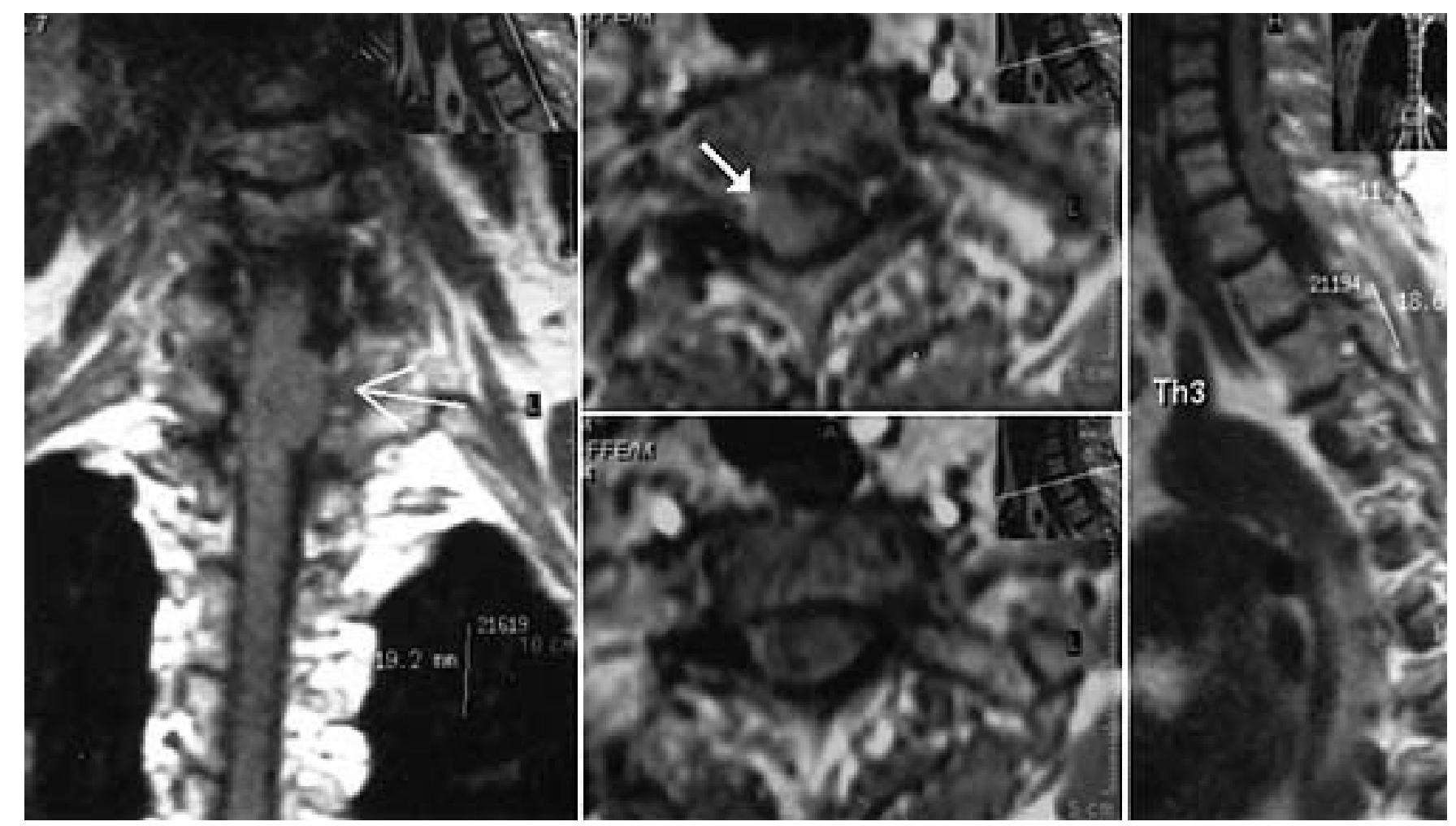

Fig. 2. Preoperative MR imaging views demonstrating a ventrolateral neuroma at C7-T1. The tumor is indicated by arrows. 


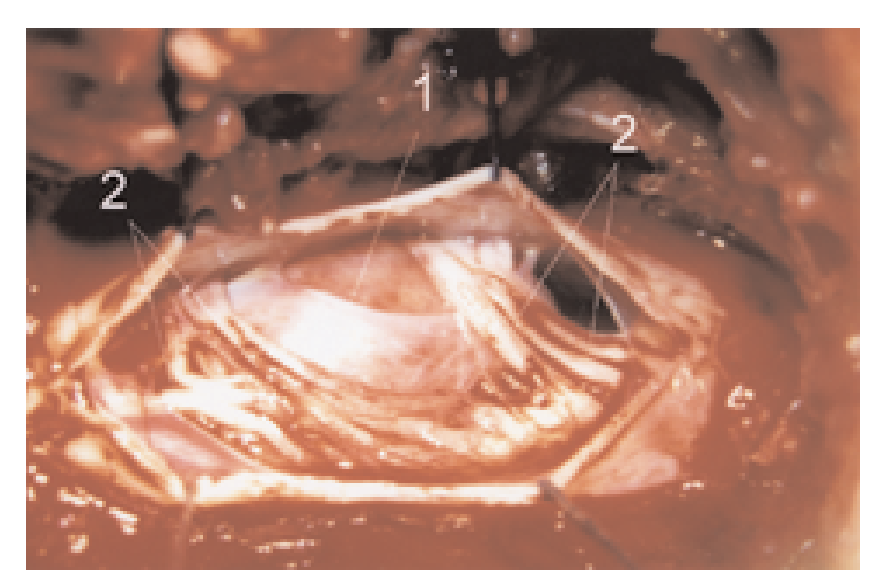

Fig. 3. Intraoperative photograph showing the dorsolateral approach for the tumor at $\mathrm{C} 7-\mathrm{T} 1.1=$ tumor; $2=$ posterior nerve roots.

The results in patients with ventral tumors were worse than in those with ventrolateral lesions (Table 9). At follow-up review, recovery was found in 76 patients, improvements in 58, no changes in four, and in two patients the neurological symptoms were worse than before the operation.

These factors were prognostically positive: operation before the appearance of severe neurological symptoms, young age of the patient, total removal of the tumor, moderate spinal cord compression, no intraoperative spinal cord traction because of adequate surgical access, and use of microsurgical techniques. As a rule, in patients who attained complete recovery there were no severe neurological signs before surgery and spinal cord compression was moderate. The patients in the group categorized as improved had more pronounced spinal cord compression, usually underwent operation after 1 to 4 years of disease progression, and exhibited severe neurological signs. In these patients their ability to work was restored after surgical intervention; however, neurological deficits remained in the form of moderate paresis and pelvic disturbances. The patients hospitalized in more serious condition and after a long period of disease progression were assigned to the group with no changes or to the group with deterioration. As a rule, in these patients surgical inter-

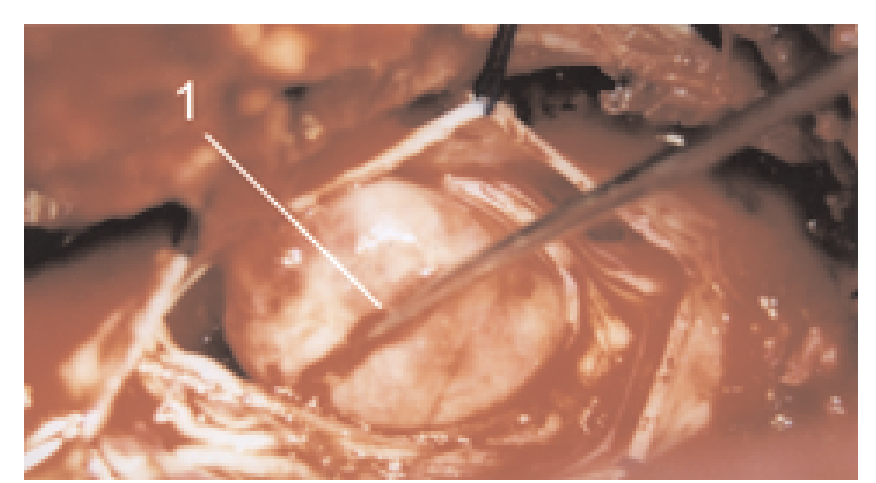

Fig. 4. Intraoperative photograph showing the tumor being mobilized with a nerve hook (1).

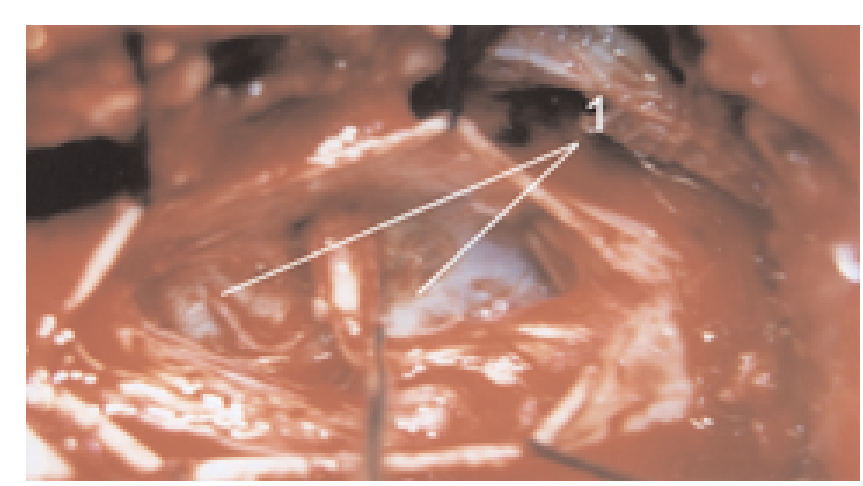

Fig. 5. Intraoperative photograph showing the cavity after the tumor was removed totally. $1=$ the sides of the tumor.

vention led to the resolution of pain or radicular signs, although neurological signs remained.

\section{DISCUSSION}

According to the latest publications, intramedullary spinal cord tumors make up $20 \%$ and extramedullary tumors account for $80 \%$ (65\% of them intradural and $15 \%$ epidural) of spinal cord lesions. Approximately $65 \%$ of intradural tumors have a dumbbell shape; they are located partially within the spinal cord canal and partially outside of it. ${ }^{7,9,10,12}$ Gottfried, et al., ${ }^{8}$ reported a metaanalysis of the literature covering 556 intradural tumors, of which 171 (31\%) were ventrally located. According to Cohen-Gadol, et al., ${ }^{4}$ of 41 patients in whom intradural tumors were found, three had ventral lesions and 10 had ventrolateral ones. Of our 360 patients, 43 had dorsal, 177 dorsolateral, 33 ventral, and 107 ventrolateral intradural extramedullary tumors.

The overwhelming majority of ventral and ventrolateral intradural spinal tumors are represented by neuromas and meningiomas but lipomas are also reported in rare cases. $^{6}$ Spinal meningiomas make up $1.2 \%$ of the total number of these types of lesions and 15 to $30 \%$ of all primary spinal tumors. Thus, according to some authors,

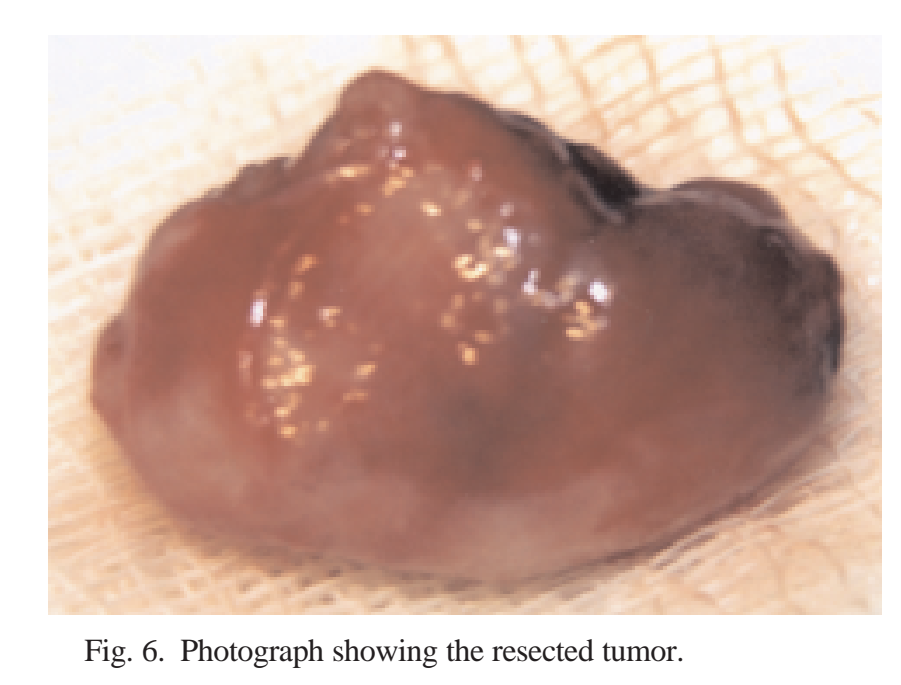




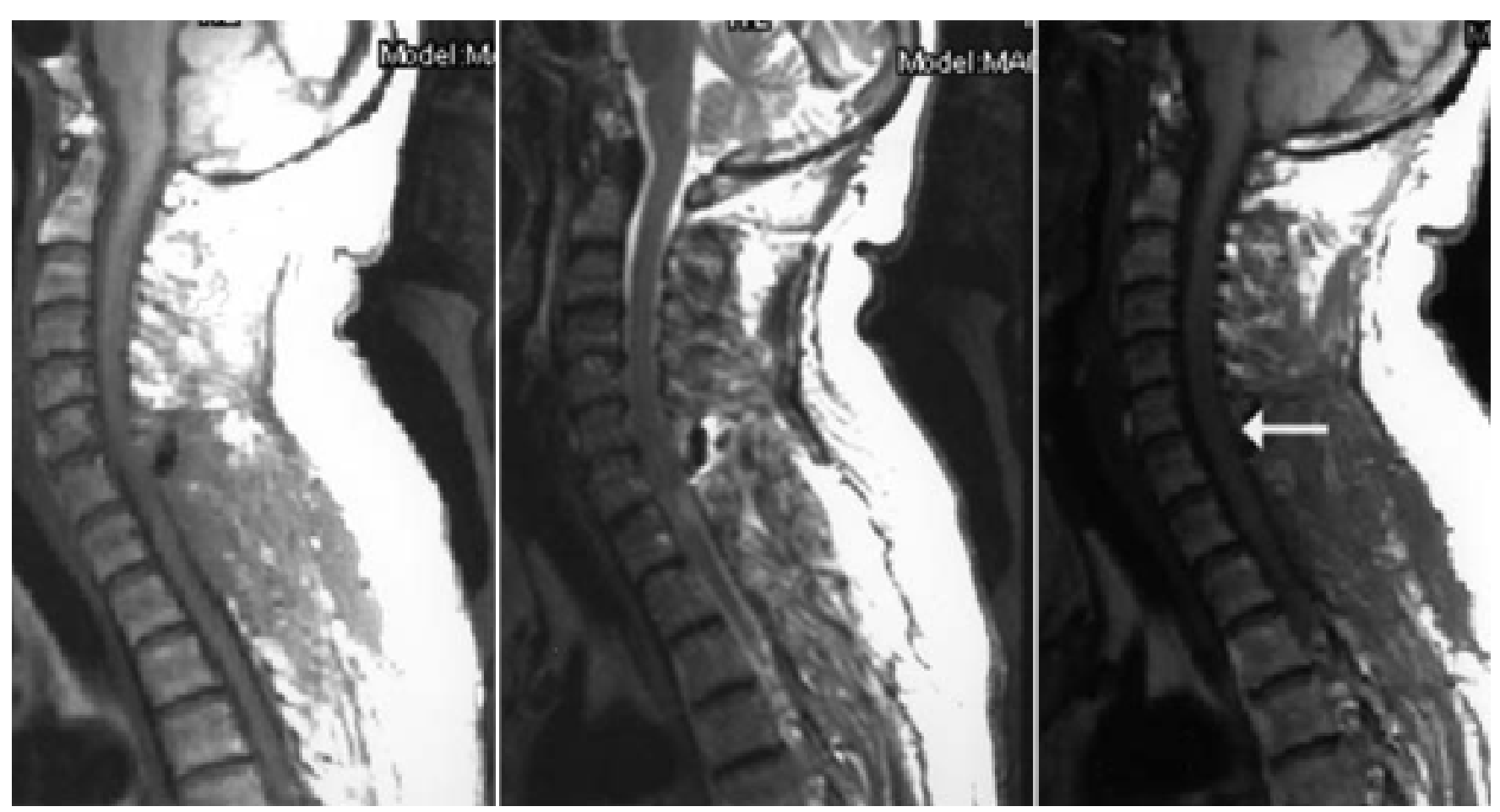

Fig. 7. Follow-up MR images obtained after surgery. Arrow indicates the side of the neuroma at C7-T1.

among intradural extramedullary spinal cord tumors meningiomas are found in $51.3 \%$ of cases and neuromas in $48.3 \%$. 1,13,14,16,17 Spinal meningiomas are frequently found in elderly people; in patients older than 60 years of age they make up $60 \%$ of all spinal tumors, and most of these meningiomas are found in the thoracic region. Neuromas are most frequently found in the cervical level and are ventrolaterally localized., ${ }^{45}$ Among spinal meningiomas, meningothelial, transitional, fibroblastic, and psammomatous forms are found more frequently, and among neuromas, schwannomas, which develop from Schwann cells mainly of the spinal cord posterior roots, are found more often. ${ }^{9,16,17}$

The optimum treatment method for ventrolateral and ventral spinal cord tumors is their total ablation. A number of authors use the dorsal median approach when removing a ventral or ventrolateral tumor. ${ }^{2}$ On revealing the tumor, on the side of its primary localization one or several dentoid ligaments are sectioned, and beside those the spinal cord is carefully taken aside. If the operative field turns out to be too narrow because of the considerable size of the tumor or its ventral location, one or more nerve roots may be sectioned to widen the operating field and prevent spinal cord trauma. ${ }^{1,8}$ In our cases if the operative field was found to be narrow because of the large size of the tumor or its ventral location, the segment's roots were preserved, but we performed facet, rib head, and pedicle resection. We generally used this access for ventral meningiomas or ventrolateral neuromas growing to the intervertebral foramen.

In cases of marked ossification and ventral location of the tumor, some authors do not remove the ossified tumor mass because of the high risk of injuring the spinal cord if there are no indications of its compression. If it is not pos- sible to perform the dural section in the matrix region of the tumor, the lesion is coagulated., ${ }^{1,6,7}$

In cases in which the tumor is located in the upper cervical spine or on the craniocervical level, some authors consider the use of dorsolateral craniospinal access ${ }^{10}$ or far lateral-lateral access to be most convenient. 2,3 According to our observations, with ventrolateral tumors of soft consistency the dorsolateral access is enough. In resection of ventral tumors, especially those of hard consistency, the use of far lateral-lateral access is necessary. Dumbbell C2 nerve-related tumors can be treated via a dorsolateral approach because of an anatomical feature consisting of the absence of an intervertebral foramen between $\mathrm{C}-1$ and C-2 and a wide C1-2 interspace. ${ }^{11}$

Surgical results varied according to the reports of different authors. For example, Gottfried, et al., ${ }^{8}$ achieved complete resection in $23(92 \%)$ of 25 patients. Nevertheless, in these earlier studies the authors analyzed all spinal meningiomas. In our series of 140 ventral and ventrolateral tumors we removed 102 (74\%) totally, 30 (21\%) subtotally, and eight (5\%) partially. Recovery after surgery was noted in 70 patients $(50 \%)$, improvement in $53(38 \%)$, no change in $10(7 \%)$, and deterioration in seven $(5 \%)$.

\section{CONCLUSIONS}

Surgical access to extramedullary tumors should be based on the location of the tumor, its spread, and the region to which it is localized. Dorsolateral access is optimum in most cases in ventrolateral meningiomas. With exceptionally ventral localization of meningiomas the ventrolateral access is most adequate, whereas in cases of ventral and ventrolateral tumors in the upper cervical spine the far-lateral approach is preferable. 


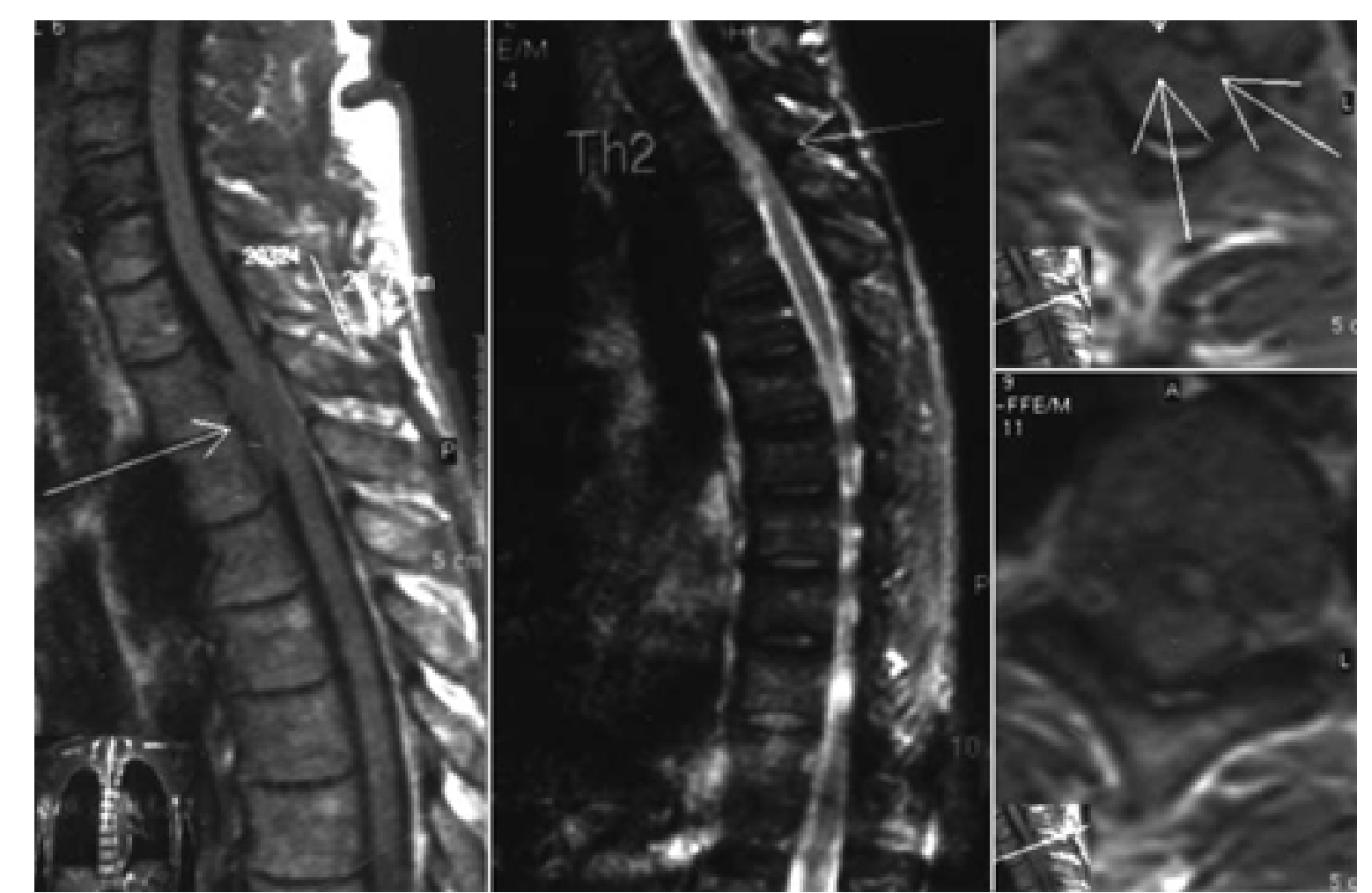

Fig. 8. Preoperative MR images demonstrating a ventral meningioma at T2-3. The tumor is indicated by arrows.

In small neuromas with dumbbell-type growth that fill the neural foramen only, dorsolateral access is needed in all regions of the spine. Extensive ventral growth of neu-
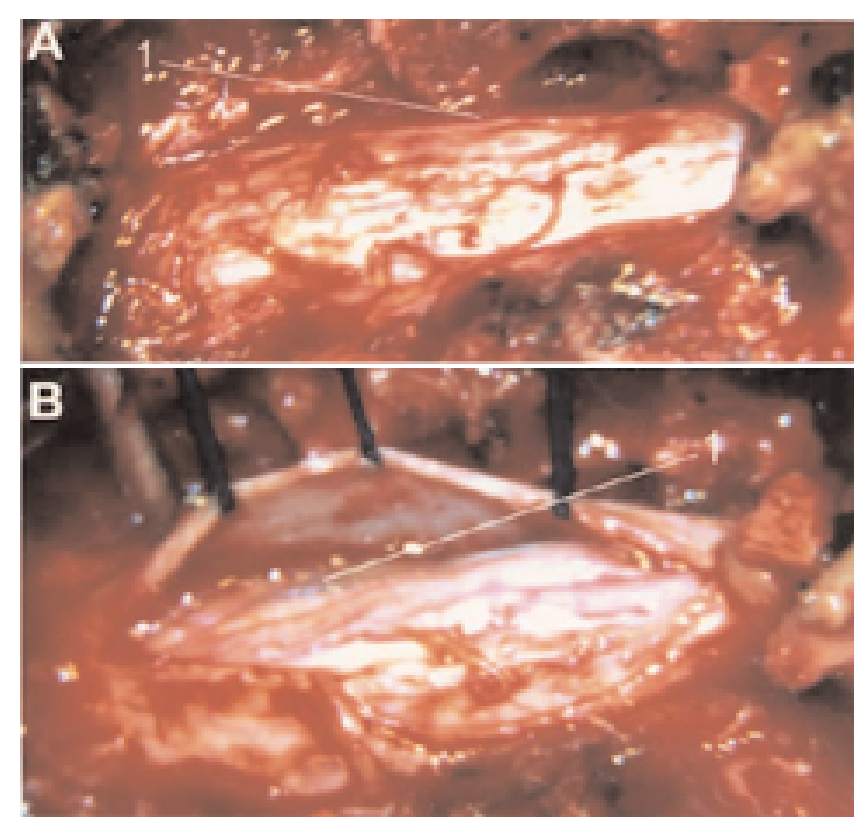

Fig. 9. Intraoperative photograph showing the dorsolateral approach for the tumor at T2-3. A: The side of extruding dura. $\mathrm{B}$ : After opening the dura via the dorsolateral approach, the lateral side of the tumor is visible (1). romas through the neural foramen in the cervical, thoracic, and lumbar spine requires the ventrolateral approach. The results in patients with ventrolaterally growing tumors were better than in those with ventrally growing ones.

The following factors were prognostically positive: early diagnosis before the appearance of severe neurological symptoms, young age of the patients, total removal of the tumor, mild spinal cord compression, no intraoperative spinal cord retraction because of adequate surgical access, and the use of microsurgical techniques.

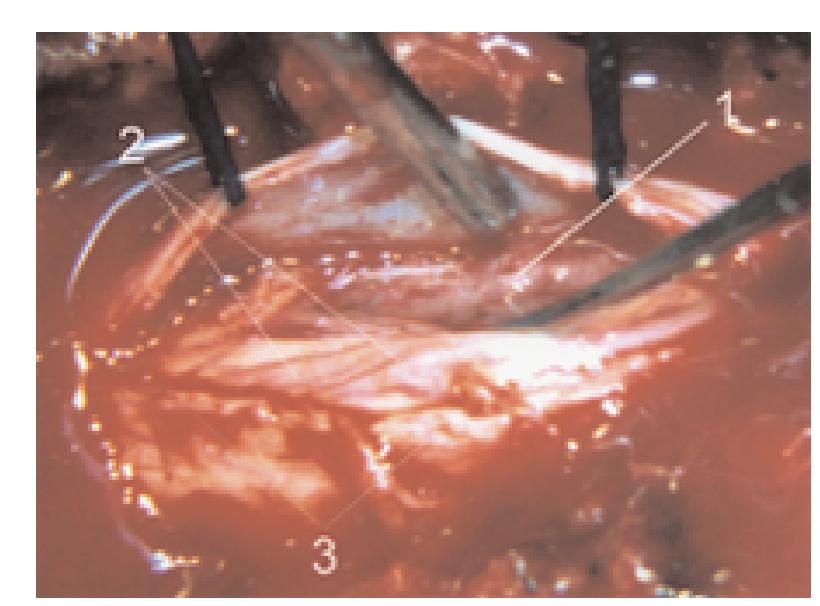

Fig. 10. Intraoperative photograph showing traction on the lateral part of the dura by sutures. $1=$ tumor that lay on the dura matter like plaque; 2 = spinal cord and nerve roots; 3 = medial part of the dura, no traction applied. 

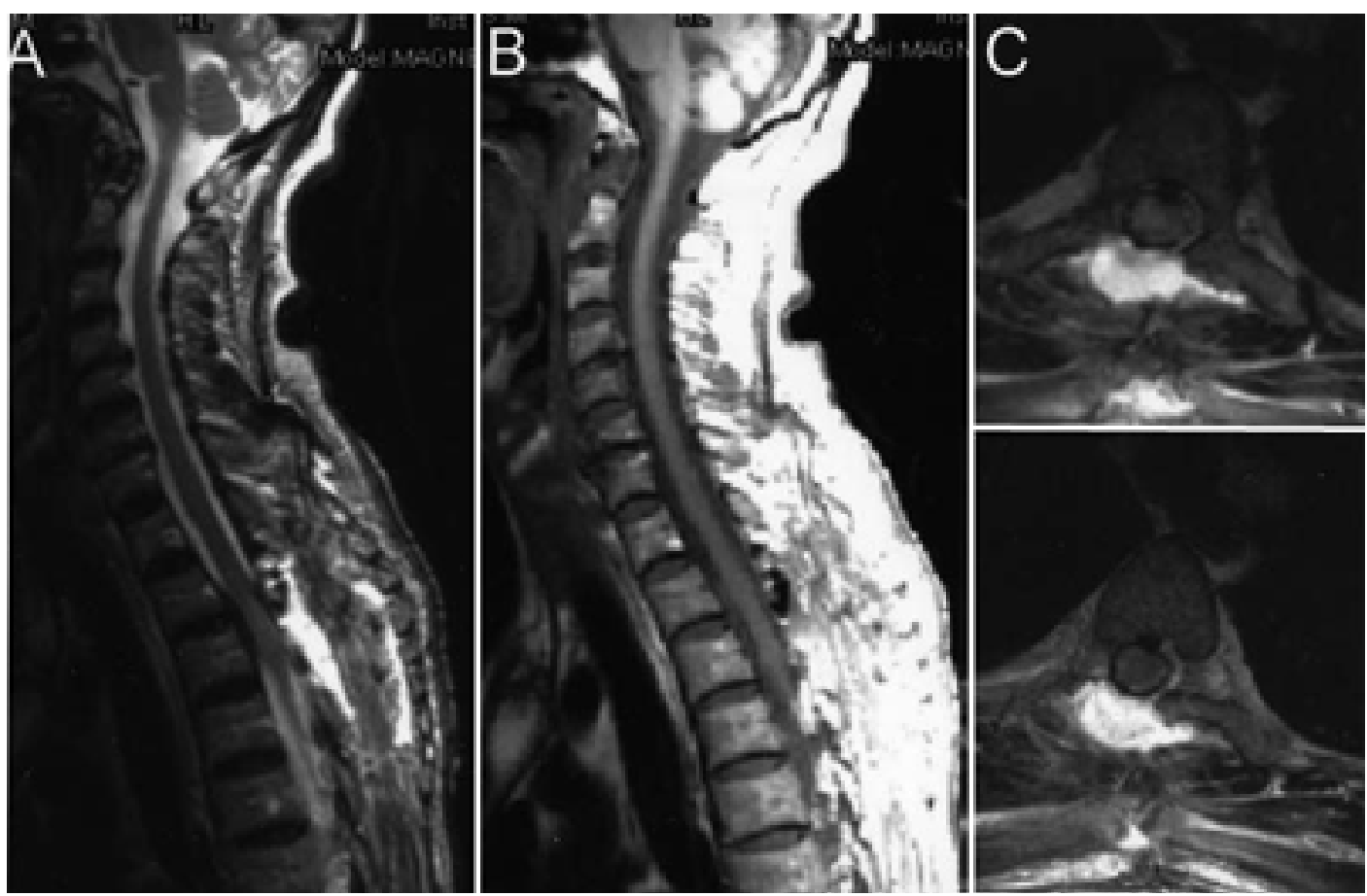

Fig. 11. Follow-up MR images obtained after surgery. On the axial image (C) the zone of removed facet and a part of the rib head on one side are visible.

TABLE 8

Completeness of removal of ventral and ventrolateral tumors

\begin{tabular}{lcccc}
\hline \hline $\begin{array}{l}\text { Extent of } \\
\text { Removal }\end{array}$ & Cervical & Thoracic & Thoracolumbar & Total No. (\%) \\
\hline total & 37 & 42 & 23 & $102(74)$ \\
subtotal & 15 & 10 & 5 & $30(21)$ \\
partial & 5 & 2 & 1 & $8(5)$ \\
\hline
\end{tabular}

\section{References}

1. Al-Mefty O: Operative Atlas of Meningiomas. New York: Lippincott-Raven, 1998, pp 249-382

2. Arnautovic KI, Al-Mefty O, Husain M: Ventral foramen magnum meningiomas. J Neurosurg (Spine 1) 92:71-80, 2000

3. Ashour A, Rautenberg M, Buhl RJ, et al: Giant ventral intradural extramedullary neuroma: case report. Neurosurgery 44: 1338-1341, 1999

4. Cohen-Gadol AA, Zikel OM, Koch CA, et al: Spinal meningiomas in patients younger than 50 years of age: a 21 -year experience. J Neurosurg (Spine 3) 98:258-263, 2003

5. Dowd GC, Zeiller S, Awasthi D: Far lateral transcondylar approach: dimensional anatomy. Neurosurgery 45:95-100, 1999

6. Fujiwara F, Tamaki N, Nagashima T, et al: Intradural spinal lipomas not associated with spinal dysraphism: a report of four cases. Neurosurgery 37:1212-1215, 1995

7. Gezen F, Kahraman S, Canakci Z, et al: Review of 36 cases of spinal cord meningioma. Spine 25:727-731, 2000

8. Gottfried ON, Gluf W, Quinones-Hinojosa A, et al: Spinal meningiomas: surgical management and outcome. Neurosurg Focus 14(6): $\mathrm{E} 2,2003$

9. King AT, Sharr MM, Gullan RW, et al: Spinal meningiomas: a 20-year review. Br J Neurosurg 12:521-526, 1998

10. Klekamp J, Samii M: Surgical results for spinal meningiomas. Surg Neurol 52:552-562, 1999

11. Kyoshima K, Uehara T, Koyama J, et al: Dumbbell C2 schwannomas involving both sensory and motor rootlets: report of two cases. Neurosurgery 53:436-440, 2003
TABLE 9

Clinical results in 140 patients with spinal cord tumors

\begin{tabular}{|c|c|c|c|c|c|}
\hline \multirow[b]{2}{*}{ Location } & \multicolumn{4}{|c|}{ Clinical Results (\%) } & \multirow[b]{2}{*}{$\begin{array}{l}\text { No. of } \\
\text { Patients }\end{array}$} \\
\hline & Recovery & Improvement & $\begin{array}{c}\text { No } \\
\text { Change }\end{array}$ & Deterioration & \\
\hline ventral & $2(1)$ & $19(14)$ & $7(5)$ & $5(4)$ & 33 \\
\hline ventrolateral & $68(49)$ & $34(24)$ & $3(2)$ & $2(1)$ & 107 \\
\hline total & $70(50)$ & $53(38)$ & $10(7)$ & $7(5)$ & 140 \\
\hline
\end{tabular}

12. Lee RR: MR imaging of intradural tumors of the cervical spine. Magn Reson Imaging Clin N Am 8:529-540, 2000

13. Levy WJ Jr, Bay J, Dohn D: Spinal cord meningioma. J Neurosurg 57:804-812, 1982

14. Mirimanoff RO, Dosoretz DE, Linggood RM, et al: Meningioma: analysis of recurrence and progression following neurosurgical resection. J Neurosurg 62:18-24, 1985

15. Nakano S, Yoneyama T, Sugimoto T, et al: Paramedian tranmuscular access to C-3 dumbbell-type neurofibroma without paravertebral muscle dissection from the spinous process or facetectomy. Technical note. J Neurosurg (Spine 1) 99: $121-124,2003$

16. Roux FX, Nataf F, Pinaudeau M, et al: Intraspinal meningiomas: review of 54 cases with discussion of poor prognosis factors and modem therapeutic management. Surg Neurol 46: 458-464, 1996

17. Solero CL, Fornari M, Giombini S, et al: Spinal meningiomas: review of 174 operated cases. Neurosurgery 25:153-160, 1989

Manuscript received February 6, 2004.

Accepted in final form June 18, 2004.

Address reprint requests to: Eugene I. Slin'ko, M.D., Ph.D., Institute of Neurosurgery N. ACAD., A. Romodanov Manuilsky st. 32, Kiev 04050, Ukraine. email: iyad@mail.ru. 